\title{
Using the Untested Ebola Drug in Ebola Affected Patients: An Ethical Dilemma
}

\author{
Neha Alang ${ }^{1, *}$ \\ 1. Internal Medicine, Newport Hospital, Newport, USA
}

*Corresponding Author: Neha Alang, MD, Newport Hospital, a Lifespan Partner, 11 Friendship Street, Newport-02840, Washington, USA Email: nalang@lifespan.org

Article History: Received: 5 Aug 2014; Revised: 20 Oct 2014; Accepted: 12 Nov 2014

Cite this article as: Alang N. Using the untested Ebola drug in Ebola affected patients: An Ethical Dilemma. Int J Travel Med Glob Health. 2015;3(1):1.

\section{Dear Editor}

The 2014 Ebola outbreak is the largest Ebola outbreak in history and the first in West Africa [1]. No specific vaccine or medicine (e.g., antiviral drug) has been proven to be effective against Ebola [2]. The standard treatment for Ebola remains supportive therapy [3]. ZMapp, being developed by Mapp Biopharmaceutical Inc., is an experimental treatment, for the use of the individuals infected with Ebola virus [3]. The product is a combination of three different monoclonal antibodies that bind to the protein of the Ebola virus [3]. The use of the drug "ZMapp" for the Ebola infection presents a huge dilemma since it could have harmful side-effects and it has not yet been tested in humans for its effectiveness [3]. The Ebola infected patients might survive the Ebola infection but may die from side-effects of the drug ZMapp which are not yet known. ZMapp may cause side-effects which may not occur immediately and may be seen much later.

Moreover, at this time very few courses of this experimental treatment have been manufactured [3] which raises issues on whom to use this drug if infected with the Ebola virus.

Since, ZMapp is an experimental drug, patients may not agree to take this drug. This may be easy if the relationship between the patient and the health care provider is good.

It will be interesting to study whether or not the Ebola infected patients who have received ZMapp develop any side-effects in future which could be related to this drug.

The Ebola infection has posed a great challenge to the anti-microbial world and has raised many questions on the readiness of health care providers to contain this infection.

\section{References}

1. Centers for Disease Control and Prevention. Ebola Hemorrhagic Fever. http://www.cdc.gov/vhf/ebola/outbreaks/guinea/ [Cited 11 December 2014].

2. Centers for Disease Control and Prevention. Ebola Hemorrhagic Fever. http://www.cdc.gov/vhf/ebola/treatment/index.html [Cited 11 December 2014].

3. Centers for Disease Control and Prevention. Ebola Hemorrhagic Fever. http://www.cdc.gov/vhf/ebola/outbreaks/guinea/qa-experimental-treatments.html [Cited 11 December 2014]. 